\title{
POVOS INDÍGENAS, DIREITO E ESTADO: ROMPENDO CÂNONES DO INTEGRACIONISMO JURÍDICO
}

INDIGENOUS PEOPLES, RIGHT AND STATE: BREAKING CANONS OF LEGAL INTEGRATIONISM

PUEBLOS INDÍGENAS, DERECHO Y ESTADO: ROMPIENDO CÁNONES DEL INTEGRACIONISMO JURIDICO

Jorge Luis Ribeiro dos Santos ${ }^{1}$

1 Professor de Direito da Universidade Federal do Sul e Sudeste do Pará/UNIFESSPA, Mestre em Ciências Criminais pela PUCS/RS, Doutor pelo Programa de Pós-Graduação em Direito da UFPA - PPGD-UFPA. 
Resumo: O artigo investiga as formas de integracionismo jurídico que fundamentou e fundamenta as relações do Estado brasileiro e empresas privadas em relação aos povos indígenas do sudeste paraense, Amazônia Oriental brasileira: Gavião Akrãtikategê, Xikrín do Cateté e Suruí Aikewara, a partir de conflitos socioambientais envolvendo tais povos com a implementação do Projeto Grande Carajás (PGC). Consoante os desdobramentos jurídicos destes, problematizou-se a lógica de operação jurídica envolvendo os povos indígenas, a produção jurídica e a aplicação do direito que perpetua os impactos, olvidando a realidade de pluralismo cultural e jurídico, as "interlegalidades" e o lugar dos direitos dos povos indígenas nestes contextos. A imposição jurídica estatal sobre tais povos justificam e fundamentam tais empreendimentos, tornando-se desta forma integracionismo jurídico sobre eles, impedindo que impactos pretéritos e presentes sejam mitigados, reparados e os direitos dos povos indígenas restaurados.

Palavras-chave: Estado e povos indígenas. Conflitos socioambientais. Direitos indígenas. Integracionismo jurídico.

Abstract: This article investigates the forms of legal reasoning and integrationism that underpin the relationship between the Brazilian state and private companies in relation to the indigenous peoples of southeast Pará, in the Eastern Brazilian Amazon: the Akrãtikategê, Xikrim Catete and Surui Aikewara, based on environmental conflicts involving these people with the implementation of Project Grande Carajás (PGC). According to their legal ramifications, it investigates the logic of the legal transaction involving indigenous peoples, the legal production and application of the law that perpetuates the impacts, forgetting the reality of the cultural and legal pluralism, the "interlegalidades", and the place of indigenous peoples' rights in these contexts. The state legal imposition on these people groups justifies and underpins such ventures, becoming legal integrationism over them, and preventing past and present impacts from being mitigated and repaired, and the rights of the indigenous peoples restored. 
Keywords: State and indigenous peoples. Environmental conflicts. Indigenous rights. Legal integrationism.

Resumen: Este artículo investiga las formas del integracionismo jurídico que fundamentó y fundamenta las relaciones del Estado brasileño y las empresas privadas en relación a los pueblos indígenas del sudeste de Pará, Amazonia Oriental brasileña: Gavião Akrãtikategê, Xikrín do Cateté y Suruí Aikewara, a partir de conflictos socioambientales que involucran a tales pueblos con la implementación del Proyecto Grande Carajás (PGC). En conformidad con los desdoblamientos jurídicos de los mismos, se problematizó la lógica de la operación jurídica relacionada a los pueblos indígenas, a la producción jurídica y a la aplicación del derecho que perpetúa los impactos, olvidando la realidad del pluralismo cultural y jurídico, las "interlegalidades" y el lugar de los derechos de los pueblos indígenas en estos contextos. La imposición jurídica estatal sobre tales pueblos justifica y fundamenta tales emprendimientos, volviéndose de esta forma integracionismo jurídico sobre ellos, impidiendo que se mitiguen y reparen los impactos pretéritos y presentes y se restauren los derechos de los pueblos indígenas.

Palabras clave: Estado y pueblos indígenas. Conflictos socioambientales. Derechos indígenas. Integracionismo jurídico.

INTRODUÇÃO

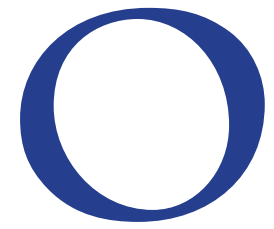

Programa Grande Carajás (PGC) foi criado pelo Decreto 1.813/80. Dentre outras deliberações, ele delimitou um espaço do sudeste do Pará o qual se supunha "homogêneo, instituído para fins administrativos, financeiros e fiscais" (ALMEIDA, 1994, p. 19). Para Almeida, o PGC configura o desenho territorial de uma região considerada necessária a um grande programa oficial e é fruto de uma imposição. O ato jurídico criador que configura a área decretada legaliza arbitrariamente uma cartografia. O PGC "organiza" 
territorialmente a coalizão de interesses empresariais e financeiros complexos que abarcam empresas transnacionais, agências financeiras multilaterais e o Estado, agências reguladoras e de planejamento estatal, empresas estatais, mineradoras, siderurgias, reflorestadoras, fábricas, madeireiras, carvoarias, agropecuaristas, guseiras, empreiteiras, indústrias de óleos vegetais, hidrelétricas e bancos, pouco levando em conta povos indígenas e populações tradicionais que ocupavam o território.

As áreas indígenas nas quais se assenta o PGC foram demarcadas e homologadas sucessivamente. Áreas de preservação ambiental (Unidades de Conservação - UC), foram criadas na zona de extração mineral da Serra de Carajás e no entorno formando o mosaico ${ }^{2}$ de Carajás. Foi demarcada, entre os anos oitenta e inícios de noventa do século passado, a Reserva Indígena (RI) Mãe Maria (Parkatêjê, Kyikatêjê e Akrãntikatêjê), em 1996, localmente conhecidos como povo indígena Gavião; pelo Decreto 88648/83, foi feita a demarcação da RI Sororó (Suruí Aykewara); a Portaria Ministerial 319/93 declarou ocupação e posse dos povos indígenas: Araweté, Assurini, Xikrín e Apyterewa. E as Unidades de Conservação também foram criadas em Carajás (Área de Proteção Ambiental do Igarapé Gelado em 1989, Reserva Biológica do Tapirapé em 1989 e no mesmo ano a Floresta do Tapirapé-Aquiri, a Floresta Nacional de Carajás e a Floresta Nacional do Itacaiúnas, criadas em 1998), formando o "escudo" ao redor da área de mineração da Vale. A TI Xikrín do Cateté completa o "escudo" geográfico de limitação socioambiental e cartográfico da região de Carajás no entorno da extração mineral da Vale (SANTOS, 2013). A FUNAI se estrutura na região, com sede em Marabá, sob a Coordenação Regional do Baixo Tocantins. A Regional do Baixo Tocantins desenvolve atividades voltadas para nove etnias sob sua jurisdição nas regiões sul e sudeste do Pará. As etnias sob a jurisdição da FUNAI local são:

2 Mosaico é o conjunto de unidades de conservação contíguas segundo a Lei do Sistema Nacional de Unidades de Conservação, conforme a Lei do Sistema Nacional de Unidades de Conservação (SNUC, Lei 9985/2000, Art. 26). 
Etnias indígenas, população e localização. Jurisdição da FUNAI Regional do Baixo Tocantins/ Marabá-PA)

\begin{tabular}{|l|l|l|}
\hline Etnia & População & Localização \\
\hline 1- Suruí Aikewara & 380 indígenas & Município de São Geraldo do Araguaia \\
\hline 2- Amanaié & 150 indígenas & Região de Ipixuna do Pará \\
\hline 3- Anambé & 130 indígenas & Região de Moju \\
\hline 4- Assuriní & 480 indígenas & Região de Pacajá \\
\hline 5- Gaviões & 570 indígenas & Município de Bom Jesus do Tocantins \\
\hline 6-Guarany-mybia & 50 indígenas & Jacundá \\
\hline 7-Xikrín do Cateté & 1.100 indígenas & Região de Parauapebas/Água Azul do Norte \\
\hline 8- Parakanan & 850 indígenas & Itupiranga \\
\hline 9- Guajajara & 55 indígenas & Itupiranga \\
\hline
\end{tabular}

Fonte: FUNAI, Marabá, 2013.

Ao situar o lugar dos direitos dos povos indígenas na região sul e sudeste do Pará, buscou-se apreender a realidade dos povos indígenas da microrregião de Marabá e dar visibilidade aos conflitos contínuos a que estão submetidos, a partir das frentes de expansão pecuária, madeireira, energética e minerária na região, bem como os conflitos advindos com os impactos socioeconômicos das políticas desenvolvimentistas implementadas nas últimas quatro décadas. Trata-se especificamente dos desdobramentos de demandas por direitos a partir de tais impactos no cotidiano de três povos indígenas localizados na região delimitada: o povo Xikrín do Cateté, o povo indígena Gavião Akrãtikategê (grupo dos Timbiras Ocidentais, conhecidos como Gavião do Oeste) da Reserva Indígena Mãe Maria e os Suruí Aikewara da Terra Indígena Sororó, pelo fato de estarem diretamente afetados pelos conflitos socioambientais advindos e acentuados com a implantação do PGC na região.

Os Xikrín do Cateté estão mais física e diretamente envolvidos com a área de extração mineral em Carajás, devido à proximidade de suas terras com as áreas de extração e prospecção mineral em Carajás. Os Xikrín vivem atualmente nas aldeias Cateté, Djudjekô e Ô-odjã, na Terra Indígena Xikrín do Cateté, no 
sudeste do Pará, que compreendia da Serra de Carajás à Serra Onça Puma, na bacia do Rio Itacaiúnas, onde hoje se situa a cidade de Parauapebas a leste até Água Azul do Norte, Ourilândia do Norte, Tucumã e São Felix do Xingu a oeste era território do povo Xikrín. No território Xikrín, justapõe-se a região central da Província Mineral de Carajás, onde, desde os anos oitenta do século passado, a Vale explora minérios do Projeto Grande Carajás (PGC). O território Xikrín limitase com a Serra do Carajás a leste, onde a Vale extrai minério em jazidas a céu aberto; Serra da Onça Puma a oeste, na qual a Vale tem projetos de exploração mineral; e atuais municípios de Água Azul do Norte a sudeste e Parauapebas ao sul. A população Xikrín hoje conta com mais de 1000 (mil) indivíduos. ${ }^{3}$

O povo Gavião, embora "confinados" na Reserva Mãe Maria, distante 20 km de Marabá, no Pará, teve suas terras cortadas pela Ferrovia Carajás, nos anos 80 do século passado e logo depois pelo linhão de transmissão elétrica da empresa estatal federal de energia elétrica, a Eletronorte. Habita a Terra Indígena Mãe Maria em área de 62.488 ha, no município de Bom Jesus do Tocantins, no Pará. É limitada a oeste pelo rio Flecheiras e a leste pelo rio Jacundá e a norte e sul por duas linhas secas. Nesta área vivem três grupos: Parkatêjê, Kyikatêjê, Akrãtikatêjê, divididos em cinco aldeias: Kupejipôkti (sede da comunidade Parkatêjê), Negão (...); Amtatí (Kyikatêjê); Akrãti (Akrãtikatêjê), e Akrãkaprêkti (Kyikatêjê) ${ }^{4}$. A junção dos três grupos em mesma Terra Indígena (hoje em aldeias separadas) não se deu em razão de necessidades dos grupos, mas em consequência dos empreendimentos governamentais da Usina Hidrelétrica de Tucuruí (UHT), que inundou o território Akrãntikatêjêe, e também a implantação das linhas de transmissão da Eletronorte, que determinaram a retirada forçada dos Kyikatêjê de sua aldeia originária da Ladeira Vermelha, e os removeu para a aldeia dos Parkatêjê" ${ }^{\prime \prime}$.

A junção administrativa federal à época na qual [o]s Kyikatêjê foram trazidos do Estado do Maranhão pela Fundação Nacional do Índio (FUNAI) deu-se no final

3 SANTOS, Jorge Luis Ribeiro dos. Xikrín versus Vale: direitos olvidados. Tese de Doutorado, Programa de Pós-graduação em Direitos Humanos - PPGD/UFPA, Belém, 2013.

4 RIBEIRO JÚNIOR, Ribamar. Entre deslocamentos e cisões: a trajetória dos Akrãtikategê na luta por sue território. II Coninter, Belo Horizonte, 08 a 11 de outubro/ 2013. Disponível em: www.2coninter.com.br/artigos/pdf/307.pdf? Acesso em: 15/01/2014.

5 RIBEIRO JÚNIOR, Ribamar. Entre deslocamentos e cisões: a trajetória dos Akrãtikategê na luta por sue território. II Coninter, Belo Horizonte, 08 a 11 de outubro/ 2013. Disponível em: www.2coninter.com.br/artigos/pdf/307.pdf? Acesso em: 15/01/2014. 
da década de 60. Os Kykatêgê foram reunidos aos Parkatêjê e aos Akrãtikatêjê no início da década de 80. Em 2001, os Kyikatêjê decidem pela cisão dos Parkatêjê e construíram nova aldeia ${ }^{6}$.

Os Suruí Aikewara, por sua vez, habitam a Terra Indígena Sororó, são índios tupis castanheiros que habitam o sudeste do Pará, entre os municípios de São Domingos e São Geraldo do Araguaia, hoje somam mais de 300 (trezentos indivíduos).

Em meados dos anos de 1960 os Aikewára sofreram uma grande de população após o contato sistemático com a população das cidades vizinhas e chegaram a 33 índios (...). Apesar de duramente perseguidos por fazendeiros e madeireiros da região, além de surtos de gripe e varíola, os Aikewára resistiram. Neste processo, no entanto, houve muita interferência por parte dos não-índios, que procuraram alterar suas práticas religiosas, sua alimentação, suas regras matrimoniais etc. Este momento mudou definitivamente o rumo da história e da cultura desta sociedade indígena. ${ }^{7}$

Estes povos foram direta e indiretamente impactados pelos efeitos minerários de Carajás e seu entorno e pelos desdobramentos dos grandes projetos minerários (Xikrín, Gavião e Suruí) e energéticos (Gavião Akrãtikategê), implementados a partir dos anos setenta do século passado no sudeste paraense. Há a invisibilidade regional sobre a realidade indígena diante dos impactos inscritos na história destes povos (e de outros da região). Predomina a ignorância pública e certo alheamento dos movimentos sociais "progressistas" da região acerca do movimento resistente indígena, além do etnocentrismo da sociedade local em relação aos diversos povos indígenas que habitavam e habitam o sudeste do Pará.

O Estado, em geral, e a ciência jurídica, em específico, têm o compromisso histórico de dar relevância teórica e analítica a tais conflitos. Os povos indígenas do

6 FERNANDES, Rosani de Fátima. Educação Escolar Kyikatêjê: novos caminhos para aprender e ensinar. Dissertação (Mestrado em Direito) - Universidade Federal do Pará, Belém, 2010.

7 NEVES, Ivânia dos Santos e CORRÊA, Maurício Neves. O povo indígena Aikewára e a GuerriIha do Araguaia: mediação, apropriação e resistência nas fronteiras de identidades. II Conferência Sul Americana/ ALAIC: "Amazônia e o direito de comunicar" 17 a 22 de outubro de 2011 - Belém/PA, 2011, p. 4. Disponível em: http://www.unicentro.br/redemc/2011/ conteudo/alaic artigos/Alaic Santos Neves.pdf. Acesso em: 15/01/2014. 
sudeste do Pará foram sistematicamente violentados pelas "frentes de expansão" ou pelas "frentes pioneiras" ${ }^{8}$, públicas ou privadas na região, desde a expansão em busca da castanha no início e meados do século passado, até o expansionismo nos anos setenta do século passado e seu agravamento nos dias atuais com as madeireiras, os grandes empreendimentos agropecuários, as hidrelétricas, as mineradoras auríferas e ferríferas, a abertura de estradas e ferrovias, dentre outros. Hoje, os empreendimentos logísticos, extrativos, industriais e agropecuários consolidaram-se, porém, a expansão não cessou e com ela a violência física e simbólica sobre os territórios indígenas ${ }^{9}$ e não somente sobre suas terras. $O$ conceito de "frentes de expansão" na Amazônia é tomado de Martins, as quais têm a peculiaridade de serem planejadas pelo Estado e vir de fora dos centros econômicos e políticos hegemônicos da sociedade brasileira, o que a difere das frentes "pioneiras" tradicionais. As frentes de expansão a que se referiu possuem características semelhantes por serem impulsionadas pelo Estado ditatorial brasileiro da década de setenta conjugado economicamente pelo capital externo. Neste cenário, os direitos dos indígenas seguem olvidados e as políticas públicas que outrora os atingiram de maneira negativa não propõem soluções restaurativas ou reparadoras. O segmento privado (e/ou público) que aufere rendas dos territórios subtraídos relega os povos indígenas a "problemas" de Estado e a continuidade dos processos de injustiça, integracionismo, e colonialismo continuam.

Na especificidade do sudeste do Pará, nas últimas 4 (quatro) décadas, a expansão se dá pela ampliação do capital, estimulado pelo Estado, em movimento de avanço e pressão sobre os territórios tradicionais dos povos indígenas. A tensão territorial se configura nos conflitos jurídicos e/ou administrativos, 8 MARTINS, José de Souza. A chegada do estranho. In: HÉBETTE, Jean (Org.). 0 cerco está se fechando. Petrópolis: Vozes; Belém: NAEA/FASE, 1991.

9 Território (Decreto 6.040/2007, Art. 231 da CF): os espaços necessários à reprodução cultural, social e econômica dos povos e comunidades tradicionais e utilizados de forma permanente ou temporária, necessário à garantia de sua organização social, costumes, línguas, crenças e tradições. Conjuga os direitos originários sobre as terras que tradicionalmente ocupam ou usam para sua reprodução cultural, social, religiosa, ancestral e econômica, utilizando espaços físicos, simbólicos e conhecimentos, inovações e práticas gerados e transmitidos pela tradição para garantir o uso equilibrado dos recursos naturais e reprodução da vida e melhoria da qualidade desta para as presentes e futuras gerações. Para Gallois, a territorialidade é "uma abordagem que não só permite recuperar e valorizar a história da ocupação de uma terra por um grupo indígena, como também propicia uma melhor compreensão dos elementos culturais em jogo nas experiências de ocupação e gestão territorial indígenas" (2001, p. 01). 
dando origem ou continuidades de lutas como: 1) para reparação de territórios subtraídos e remoção forçada, como é o caso dos Akrãtikategê, os quais foram involuntariamente removidos de seu território por conta da inundação do lago formado pela represa da Hidrelétrica de Tucuruí. Os Akrãtikategê lutam desde 1989 na Justiça Federal contra a Eletronorte para que esta os indenize com outras terras para assentamento da Aldeia Akrãtikategê. Em 2012 a Justiça Federal deferiu o pedido, mas a execução está pendente de análise de recurso impetrado pela Eletronorte; 2) a luta por retomada e ampliação de territórios e mitigação de impactos rodoviários e antrópicos, como é o caso dos Suruí, os quais impetraram requerimento junto à FUNAI para reaver territórios dos quais foram expulsos por fazendeiros. O procedimento administrativo tramita desde 2003. As áreas reivindicadas foram identificadas pela FUNAI e o processo encontra-se sob a apreciação do Ministério da Justiça para revisão de limites; 3) os conflitos por mitigação de impactos minerários advindos da extração mineral da Vale em Carajás e de subtração de territórios com a criação da FLONA (Floresta Nacional) de Carajás, para concessão de extração minerária da Vale S.A ${ }^{10}$. A Vale, desde o início do PGC, está obrigada a repassar recursos financeiros aos Xikrín. No entanto, a empresa suspendeu o repasse de recursos em dezembro de 2006, por conta de protesto de ocupação de Carajás pelos Xikrín. A Justiça Federal liminarmente obrigou-a a restituir os repasses financeiros. A Vale já impetrou 7 (sete) recursos, e o processo segue no Tribunal Regional Federal, em Brasília, sem resultado definitivo. Por outro lado, lideranças Xikrín subscreveram requerimento ao Ministério Público Federal em Marabá, solicitando revisão de demarcação de seu território e reivindicando área de povoamento ancestral Xikrín em Carajás, englobando núcleo urbano de Carajás e áreas de mineração da Vale. Os procedimentos administrativos pela FUNAI ainda não se iniciaram.

Tais fatos permitem discutir os direitos dos povos indígenas no contexto conflitivo que emerge dos antagonismos e contenciosos, mesmo que relegados à invisibilidade ou ao escamoteamento social, mas que por efeito acabam judicializados ou postos em conflitos frente ao Estado ou interesses privados ${ }^{11}$. 10 A Companhia Vale do Rio Doce (CVRD), hoje denominada Vale, foi estatal brasileira criada nos anos quarenta e privatizada em 1997, sendo hoje uma das maiores mineradoras multinacionais do mundo.

11 Exemplos: Ação Civil Pública, ajuizada FUNAI e Ministério Público Federal, a partir de confli- 
Estado, na forma judicante ou administrativa, depara-se com a diversidade na manifestação do pluralismo (direito estatal e direitos indígenas tradicionais, conflitos socioambientais, entre outras demandas). Reconhecê-los e dar provimento às demandas materiais que o pluralismo reclama, eis a questão que se põe em apreço. O judiciário e o executivo podem até referendar direitos indígenas, no entanto, o ponto de vista e a temporalidade dos povos indígenas parece não ter lugar na rotina processual jurídica nem, tampouco, nas decisões administrativas e políticas públicas. A estas formas de olvidar direitos é que se chama de integracionismo jurídico, ou seja, a tutela e a invisibilidade dos povos indígenas, o não reconhecimento da diversidade cultural destes povos. O integracionismo jurídico que se suscita parte da crítica ao integracionismo cultural a que se reportam autores como Cunha ${ }^{12}$, Clavero $^{13}$ e Tourinho Neto ${ }^{14}$.

O alcance da hermenêutica constitucional, internacional e infraconstitucional, da doutrina constitucional e dos nossos tribunais, no que diz respeito aos direitos interétnicos e pluriculturais, é tímido diante das demandas jurídicas históricas de tais povos. O direito internacional, constitucional e o direito comparado podem proporcionar os avanços "evitados" ou olvidados no que diz respeito à consideração e ao reconhecimento da integridade de direitos dos povos indígenas.

Para situar os direitos indígenas como alteridade jurídico-normativa frente ao direito estatuído pela sociedade ocidental e sacralizado pelos tribunais, o que extrapola a situação dos direitos meramente indígenas positivados pela cultura jurídica ocidental para os povos indígenas, implica pensar na amplitude de categorias desgastadas pela saturação de uso (ou desuso), mais abstratas e to entre Xikrín e Vale S.A, em 2006. Decisão de $1^{\text {a }}$ e $2^{a}$ instâncias obrigam a Vale a restituir mensalmente os repasses. A Vale recorreu, o processo tramita no Tribunal Regional Federal em Brasília (Processo: 2006.39.01.001068-0); Ação em que a Eletronorte é chamada a comprar terras para compensar a área dos Akrãtikategê (Gavião da Montanha) inundadas pela barragem da Hidrelétrica de Tucuruí, tramitando desde 1989 na Justiça Federal e teve decisão que favorável aos indígenas. A Eletronorte interpôs embargos, os quais estão pendentes de decisão (Processo n. 89.00.01377-7); e o processo Administrativo de revisão de limites do território do povo Suruí, tramitando no Ministério da Justiça.

12 CUNHA, Manuela Carneiro da. Índios no Brasil: história, direitos e cidadania. São Paulo: Ed. Claro Enigma, 2012.

13 CLAVERO, Bartolomé. Derecho Indígena y cultura constitucional en América. Madrid: Siglo Vieinteuno, 1994.

14 TOURINHO NETO, Fernando da Costa Tourinho, 2002, "Os povos indígenas e as sociedades nacionais: conflito de normas e superação". In: LIMA, André (Org.). O Direito para o Brasil Socioambiental. Porto Alegre: Sergio Antonio Fabris Editor, 189-229. 
discursivas do que instrumentais de defesa. Implica questionar o que tais categorias reclamam de ressemantizações e também de amplificações no sentido de resgatar significados capazes de reativar e retraduzir postulados rumo à reflexão jurídica capaz de informar a voz dos agentes históricos silenciados pela cultura jurídica do Estado, tais como os povos indígenas. Implica também exercício de "desobstrução" dos processos de invisibilidade, construídos jurídica e administrativamente, dentro de um quadro teórico que questiona o pluralismo formal e busca ampliar princípios e direitos à tradição, à diversidade e à pluralidade à luz da legislação vigente (constitucional e internacional) e para além da Constituição.

Neste sentido, o artigo discute formas monocráticas e o integracionismo jurídico, que fundamentou e fundamenta as relações do Estado e das empresas privadas com os povos indígenas do sudeste paraense, com destaque para os impactos de tais práticas sobre o povo Gavião Akrãtikategê, Xikrín do Cateté e Suruí Aikewara. Parte-se de tais conflitos socioambientais envolvendo povos indígenas no contexto parcial do sudeste paraense, os quais se aceleraram com a implementação da grande mineração em Carajás, pela antiga Companhia Vale do Rio Doce (CVRD), com a Hidrelétrica de Tucuruí, nos anos 80 do século passado e abertura de estradas e Ferrovia Carajás, empreendimentos estes conjugados na estrutura do Projeto Grande Carajás (PGC).

Tais projetos impactaram de forma permanente os povos indígenas locais, notadamente o povo Xikrín do Cateté com a mineração nas adjacências de seu território, o povo Akrãtikategê, com a inundação de seu território pela construção da Hidrelétrica de Tucuruí ou pressões antrópicas com abertura de estradas e ferrovia, e o povo Suruí Aikewara como consequência indireta deste conjunto de impactos. Consoante os conflitos socioambientais e os desdobramentos jurídicos destes, critica-se a lógica de operação jurídica perante o conflito socioambiental envolvendo os povos indígenas e a produção jurídica e a aplicação do direito pautados no monismo e no dogmatismo jurídico diante da realidade caracterizada pelo pluralismo cultural e jurídico, o local e o grau de reconhecimento que o Estado brasileiro faz ou não dos sistemas jurídicos indígenas imbricados neste contexto, assim como as "interlegalidades" constituintes da sociedade plural como é a brasileira, consoante os marcos do pluralismo consagrado na Constituição 
do Brasil, nas Convenções internacionais e nas atuais tendências críticas ao integracionismo jurídico estatal.

Não se trata diretamente sobre análise social, antropológica, histórica ou econômica de tais impactos sobre povos indígenas, mas das relações jurídicas estabelecidas a partir de tais impactos, buscando determinar o lugar dos direitos dos povos indígenas nestes impactantes contextos e a medida da imposição jurídica estatal sobre tais povos que justificam e fundamentam tais empreendimentos, ou seja, as investidas do que se denomina de tentativas de integracionismo jurídico, que olvida outras formas de dizer o direito a partir da tradição dos povos indígenas.

\section{POVOS INDÍGENAS, AKRÃTIKATEGÊ E SURUÍ: REATUALIZANDO}

DIREITOS

O povo indígena Xikrín do Cateté foi e continua sendo impactado pela extração mineral em Carajás, seja de forma direta ou indireta, principalmente pela antropização do entorno de seu território (doenças, intrusão no território, perdas culturais, exploração clandestina de recursos, ameaça à segurança alimentar, conflitos e cisões internas por motivações e interferências não indígenas, etc). Embora a Vale efetue repasses financeiros indenizatórios ao povo Xikrín, estes recursos não são reconhecidos como indenizações, mas mera liberalidade segundo a empresa ${ }^{15}$. Tanto é fato que a empresa suspendeu tais repasses financeiros em 2006, só vindo a retomá-los no ano seguinte por determinação judicial (Ação Civil Pública - ACP), cujo processo ainda não respondeu terminantemente sobre tais deveres obrigacionais de impactos socioambientais. O processo tramita ao largo da oitiva Xikrín e os impactos socioambientais perpetuados não são objeto de apreciação judicial, limitando-se a discussão jurídica ao direito civil contratual advindo da concessão minerária em Carajás. A reinvindicação de revisão territorial impetrada por lideranças Xikrín, por sua vez, esbarra na temporalidade estendida pela burocracia administrativa e dificilmente suplantará decretos autoritários de demarcação restritiva de outrora, ou contemplará a oitiva prévia para aferimento 15 SANTOS, Jorge Luis Ribeiro dos. Xikrín versus Vale: direitos olvidados. Tese de Doutorado, Programa de Pós-graduação em Direitos Humanos - PPGD/UFPA, Belém, 2013. 
tradicional do território Xikrín suprimido pela legalidade unívoca dos interesses estatais da época, sem atualização de direitos estatais contrapostos a direitos indígenas tradicionais.

O povo Akrãtikategê, por sua vez, luta para reaver territórios em compensação ao deslocamento forçado de seu povo quando da construção da Hidrelétrica de Tucuruí, que inundou seu território ancestral. O processo contra a Eletronorte tramita em juízo desde 1989 sem solução para os Akrãtikategê. A luta também se desenrola pela via única do direito processual que ignora a temporalidade e a cosmologia indígena quanto à liquidez e certeza dos direitos territoriais subtraídos. A história e a tradição são sepultadas também na vala comum do direito estatal integracionista que se estende no tempo, mesmo que novos direitos de tradição e território tenham se inaugurado com os paradigmas da Constituição de 1988 e da Convenção 169 da OIT, só por si bastantes para restauração dos direitos subtraídos.

Os Suruí, por sua vez, sofreram impactos diretos com a colonização da região do "Bico do Papagaio"16, depois com a intromissão do Exército brasileiro na abertura de estradas sobre seu território, com objetivos de conter a Guerrilha do Araguaia, que se estabeleceu na região nos inícios dos anos setenta do século passado e com a antropização do entorno territorial, direta e indiretamente como efeito da atração migratória exercida pelos PGC e políticas de abertura rodoviária do governo militar. Este povo hoje ainda luta para reaver territórios subtraídos quando da demarcação de suas terras e investidas de posseiros, fazendeiros e assentamentos rurais do Instituto Nacional de Colonização e Reforma Agrária (INCRA). A correlação de forças da agropecuária parece ditar e sobrepor os direitos de posse e propriedade particular da terra sobre direitos territoriais tradicionais e coletivos dos povos indígenas. Pela morosidade administrativa no processo de revisão, o Estado dá continuidade e validade vertical à legalidade demarcatória de segregação e confinamento dos Suruí ao território que hoje se apresenta inviável para a reprodução cultural dos mesmos, posto que ilhado em uma parte ínfima daquele que antes fora seu território tradicional, hoje ocupado pela invasão do gado e das fazendas.

16 Região situada na confluência dos Rios Araguaia e Tocantins, onde se localiza a tríplice divisa entre os estados do Maranhão, Pará e Tocantins, no Norte do Brasil. 
No conjunto de tais conflitos, não há o reconhecimento jurídico de impactos por parte do PGC/Vale, tampouco das iniciativas governamentais pretéritas e presentes, para se estabelecer o alcance de tais impactos e juridicamente imputar responsabilidades, revisões territoriais, indenizações restaurativas e mitigatórias. Contudo, mesmo invisibilizados na formalidade estatal, empresarial ou jurídica, tais conflitos persistiram desde que o PGC/Vale iniciou trabalhos de prospecção em Carajás e se acentuou com sua consolidação e a Eletronorte construiu a barragem da Hidrelétrica de Tucuruí para fornecer energia para os projetos minerários e siderúrgicos locais. É certo que à época de tais empreendimentos não havia o arcabouço jurídico de defesa socioambiental que se tem hoje. Mas tal fato não retira a atualização dos direitos infringidos no passado, tampouco as indenizações e as reparações presentes e passadas, mesmo porque tais impactos não cessaram no tempo, assim como a não oitiva de tais povos, a partir de sua localidade tradicional, se perpetua.

Os impactos sofridos pelos povos indígenas desta região que se aceleram vertiginosamente com o PGC, nem tampouco dos direitos violados que possibilitaram a viabilidade de tais projetos. Mesmo assim, com todo arcabouço jurídico reformulado que garante direitos constitucionais, internacionais e infraconstitucionais aos povos indígenas, é preciso potencializá-lo em aspectos que este ainda não avançou. E mesmo com positivas intenções, os direitos positivos e estatais dos povos indígenas podem se instrumentalizar contaminados por amarras integracionistas, assimilacionistas e etnocêntricas, consubstanciando o que se denomina de integracionismo jurídico. A análise das implicações jurídicas a partir de recortes inspirados nos conflitos citados podem suscitar situações capazes de expandir possibilidades hermenêuticas de forma que Direito e o Estado possam questionar seus limites, democratizar inclusões e práticas inserindo novos sujeitos invisibilizados na distribuição da justiça e na efetividade do pluralismo jurídico, desconstruindo desta forma o integracionismo jurídico de tais povos.

\section{POR UMA HERMENÊUTICA DA INTERLEGALIDADE PLURALIZANTE}

Para compreensão da dimensão e da atualização dos direitos dos povos indígenas, para além dos seus direitos contemporâneos positivos e discussão 
acerca dos limites destes - não olvidando toda sua carga de conquistas das lutas indígenas e aliados -, categorias como a interlegalidade e o pluralismo jurídico são centrais. A denotação de "interlegalidade" e de direitos tradicionais indígenas também são centrais nos marcos jurídicos e teóricos propostos. A interlegalidade tomada como fenômeno situado no quadro teórico do pluralismo jurídico também deriva da "sobreposição, articulação e interpenetração de diversos espaços jurídicos"17. Trata-se de processo dinâmico, no qual os diferentes espaços jurídicos não são sincrônicos e os códigos se misturam, se fragmentam e se interpenetram, porque o universo jurídico é policêntrico. Há limites no ordenamento jurídico estatal, mas também porosidades à interpenetração dos direitos indígenas tradicionais, aí pode se dar a interlegalidade. Tal dinâmica se revela, delimitando o que se entende por direitos indígenas tradicionais, vetor da interlegalidade. Direitos indígenas tradicionais são aqueles gestados na própria voz dos protagonistas indígenas, a partir da sua tradição e oitiva em movimento de interlegalidade com o direito estatal indígena e/ou comum. Trata-se direito indígena como aqueles construtos normativos pós-assimilacionistas e pósintegracionistas que visavam integrar os povos indígenas "à comunhão nacional", que não consideravam a tradição indígena, a autodeterminação e a autonomia, a exemplo do Estatuto do Índio no Brasil, mas que foram superados no plano normativo pela Constituição de 1998 e Convenção 169 da OIT $^{18}$.

Ao aplicar o direito meramente estatal, olvida-se de outro direito indígena tradicional que deve ser confrontado com o direito estatal. $O$ reconhecimento dos direitos indígenas tradicionais imprime novas lógicas na racionalidade jurídica, principalmente em situações em que o conflito entre direitos indígenas versus direitos comuns não garantem suficientemente os direitos indígenas tradicionais ou estatais. O direito dito pelos povos sobre o que lhes afete os modos de vida, em consequências de atos estatais ou privados na ordem judicial, administrativa ou legislativa é premissa do exercício da faculdade e garantia de autodeterminarem o que é melhor para a manutenção dos seus modos de vida. E dizer o direito a partir da própria tradição é uma das manifestações da autodeterminação. ${ }^{19}$

17 SANTOS, Boaventura de Sousa. Crítica da razão indolente: contra o desperdício da experiência. São Paulo: Cortez, 2001, p. 221

18 SANTOS, Jorge Luis Ribeiro dos. Xikrín versus Vale: direitos olvidados. Tese de Doutorado, Programa de Pós-graduação em Direitos Humanos - PPGD/UFPA, Belém, 2013.

19 Ibdem, p. 243. 
A partir dos impactos exemplificados, consubstanciado na tradição jurídica indígena e no direito nativo, o direito indígena tradicional pode penetrar nas frestas judiciais e administrativas do Estado. O esforço teórico e prático é pelo reconhecimento material de agentes sociais como são os povos indígenas ou outros, portadores de uma "ecologia jurídica" que parece ignorada pelas políticas sociais e pelos espaços jurídicos. Os povos indígenas não são alcançados pela precária distribuição da justiça ou são invisibilizados pela instrumentalidade judicial e administrativa. Contudo, começam a requerer, em tempos recentes, espaços cada vez maiores nos entremeios teórico-jurídicos, ao menos no cenário de construções críticas do direito contemporâneo, desta forma, questionando também as investidas do integracionismo jurídico. E integracionismo jurídico aqui deriva das noções antropológicas do integracionismo a que foram submetidos os povos indígenas e autóctones nas mais diversas partes do mundo pelo colonialismo. Silva ${ }^{20}$ afirma que o integracionismo do Estado sobre os povos indígenas culmina por "desintegrá-los". Para o autor, a definição de "índio" é como "um orientalismo à americana".

[o]s discursos indigenistas continuam sendo proferidos a respeito dos "índios" independentemente do que eles pensam de si mesmos. O discurso indigenista, enfim, não se apresenta na atualidade de um discurso sobre o "índio", mas um discurso de exploração do "índio" para governos e governantes. É suficiente notar, a partir desta conclusão, o risco que correm os "índios" quando são julgados por sua aparência e práticas culturais, tendo em vista as representações e valores não indígenas. Também é suficiente notar, a título de hipótese, a reprodução estereotípica dos mitemas indigenistas do período colonial até o presente. Os feixes de relações acima apresentados e identificados constituem a principal contribuição desse exercício interpretativo, principalmente, num momento quando, no Brasil, os direitos indígenas aos seus territórios são questionados, tendo em vista argumentos que levantam suspeitas sobre sua aparência ou grau de aculturação, sua lealdade à pátria ou sua utilidade ao desenvolvimento regional e nacional. Se a moldura mítica acima esboçada servir de fato, enquanto estrutura inconsciente, às atitudes e reflexões indigenistas atuais, os resultados das políticas indigenistas se mostrarão extremamente

20 SILVA, Cristhian Teófilo da. Relatos de um certo Ocidente: o indigenismo como orientalismo à americana. Revista de Estudos Paraenses sobre as Américas, v.1, 2009, p. 1227. Disponível em: <http://www.red.unb.br/index.php/repam/article/view/1367>. Acesso em: 25 abr. 2011, p. 27 
previsíveis. Quer dizer, a graduação de humanidade entre "índios" e "nacionais" continuará sendo estabelecida por intermédio de concepções de "riqueza" e "desenvolvimento" com a consequente moral que supõe os primeiros como inferiores e subordinados aos segundos ${ }^{21}$.

Os povos indígenas continuam vítimas de colonialismo interno, de integracionismo que os desintegra. As relações jurídicas desempenham papel crucial neste contexto, pois o direito legitima ou não as investidas de políticas governamentais que incidem sobre os povos indígenas e seus territórios. Questionar as bases jurídicas é caminhar no restabelecimento construtivo de relações simétricas no reconhecimento de saberes jurídicos diferenciados, é tratar o direito ocidental questionando a matriz jurídica da prática cultural coercitiva, hoje hegemônica22 (SILVA, 2009).

O direito de origem eurocêntrica é o construto jurídico moderno que se inseriu nos contextos coloniais, persiste nos cenários pós-coloniais e reproduz historicamente a matriz da imposição colonial do "Norte", entendido como metáfora da prática sociopolítica da dominação, inclusive jurídica. E isto se reproduz em relação aos povos indígenas impactados por projetos desenvolvimentistas implantados no sudeste paraense desde a década de setenta. ${ }^{23}$.

Santos destaca a tensão entre o direito regulatório e o direito emancipatório ${ }^{24}$ ao afirmar que o direito deve ser contra-hegemônico e tradutor da justiça social para os grupos historicamente subordinados ou invisibilizados. E nesta persecução situam-se os povos indígenas. Postular e estender reflexões para além do direito regulatório positivado em tentativa de "reinvenção" pós-colonial do direito se torna imprescindível para se investigar os direitos dos povos indígenas. Santos defende a contra-hegemonia de grupos e lutas emergentes no cenário

21 Ibdem, p. 27.

22 SILVA, Cristhian Teófilo da. Relatos de um certo Ocidente: o indigenismo como orientalismo à americana. Revista de Estudos Paraenses sobre as Américas, v.1, 2009, p. 1227. Disponível em: <http://www.red.unb.br/index.php/repam/article/view/1367>. Acesso em: 25 abr. 2011.

23 SANTOS, Jorge Luis Ribeiro dos. Xikrín versus Vale: direitos olvidados. Tese de Doutorado, Programa de Pós-graduação em Direitos Humanos - PPGD/UFPA, Belém, 2013, p. 174.

24 Santos propõe a "emancipação" reinventada no contexto pós-colonial, que em parte origina-se da contra-hegemonia de construir justiças, igualdades e reconhecimentos das "epistemologias do Sul" (SANTOS, 2004; SANTOS, 2007). 
local e translocal que rompem com os paradigmas positivistas com a "revolução democrática da justiça" diante da exaustão paradigmática do direito. ${ }^{25}$

Para o direito relativo aos povos indígenas tais pressupostos são relevantes diante da crise do direito perante a diversidade que reclama com mais veemência a intensidade do pluralismo de fato. Wolkmer ${ }^{26}$ identifica a crise do direito no Brasil, pois o direito não mais responde às expectativas dos grupos emergentes, os quais são os protagonistas do novo direito na luta dos movimentos sociais contra a pretensão jurídico-monista do Estado. Este é o cerne da tese jus-pluralista. Embora o autor não trate especificamente dos direitos dos povos indígenas, é inegável que o pluralismo jurídico é fundamental para a compreensão dos referidos direitos. Lyra Filho ${ }^{27}$ concebe o direito nascido na dialética social dos conflitos e critica o positivismo como forma de direito instrumentalizado pelos dominadores. Partindo da dialética jurídica proposta por Lyra Filho (embora o autor não teorizasse sobre povos indígenas, mas sobre categorias sociais subordinadas e dominantes), podese situar os direitos dos povos indígenas como alteridade frente ao direito estatal. A medida da síntese entre direitos indígenas tradicionais e direitos estatais dita a intensidade de graus de justiça que o Estado permite construir para se focalizar a desconstrução do integracionismo jurídico. O propósito dialógico de traduzir direitos indígenas tradicionais sintetizando-os junto aos direitos estatais nos situa (com raras exceções) no horizonte da utopia, sem significar impossibilidade de realização, a despeito dos impactos contínuos que estes três povos sofrem e a não realização de seus direitos mitigatórios profundos.

Santos afirma que a concepção emancipatória, à qual denomina de pósmodernismo de oposição, propõe a pluralidade de projetos coletivos articulados de modo não hierárquicos por procedimentos de tradução, em vez da renúncia aos projetos coletivos, a pluralidade e a construção de uma ética a partir de baixo, ao sincretismo acrítico ele propõe a mestiçagem ou a hibridação com consciência das relações de poder que nela intervém e investigue com o que e em que 25 SANTOS, Boaventura de Sousa. Para uma revolução democrática da justiça. São Paulo: Cortez, 2007.

26 WOLKMER, Antônio Carlos. Pluralismo jurídico: fundamentos de uma nova cultura no direito. São Paulo: Alfa-ômega, 1994 e WOLKMER, Introdução ao pensamento jurídico crítico. São Paulo: Saraiva, 1995.

27 LYRA FILHO, Roberto. O que é direito? São Paulo: Brasiliense, 1995. Coleção. Primeiros Passos, 26. 
contextos e objetivos se hibridam, ao universalismo, à unilinearidade da história, às totalidades hierárquicas e propõe "a ênfase na pluralidade, na heterogeneidade, nas margens ou periferias" (2005, p. 11). E este é lado obscurecido pelo Estado ao se tratar de questões indígenas que o direito ainda não ousou transpor.

Herrera Flores ${ }^{28}$ (2004), ao tratar dos direitos humanos, alerta para o que denomina de "el malestar de la emancipacion", que para ele se resume na conquista da igualdade de direitos (herança liberal), mas que não parece ter impulsionado o reconhecimento das diferenças, pois, "el afán homogeneizador ha primado sobre el da pluralidad y diversidad" (HERRERA FLORES, 2004, p. 72). O erro do direito e do Estado ao (des)tratar a temática dos povos indígenas é se sobrepujar às artimanhas da homogeneização, caindo assim num integracionismo ou colonialismo jurídico.

O direito, nesta perspectiva de interpenetração entre saberes jurídicos diversos, pode transcender posturas homogeneizantes de quaisquer índoles político-filosóficas e insere-se nos novos lugares da crítica da produção e da instrumentalização do conhecimento. Somos herdeiros do saber jurídico que é, hegemonicamente, produzido pelo Ocidente, difundido pela racionalidade estatal em ciência e burocracia do poder e da regulação. O Estado impõe sua legalidade sobre povos etnicamente diferenciados como os indígenas, os quais não deixaram de reproduzir formas normativas próprias e consuetudinárias, a despeito da pretensa universalização e da univocidade totalizante da ciência jurídica e das estruturas estatais.

Para Rios, ${ }^{29}$ há o alargamento dos direitos na abertura constitucional que deve ser explorada na defesa dos direitos humanos diante do paradigma do sujeito de direitos identificado com o homem, o branco, o ocidental padrão do sujeito de direitos. O marco jurídico a ser inaugurado funda-se no princípio da diversidade para a defesa dos mais vulneráveis e no resgate da dignidade dos grupos ou indivíduos vitimizados. Para ele a justiça tradicional lida com esquemas 28 HERRERA FLORES, Joaquín. Los derechos humanos en el contexto de la globalización: tres precisiones conceptuales. In: SÁNHEZ RUBIO, David et al. (Orgs.). Direitos humanos e globalização: fundamentos desde a teoria crítica. Rio de Janeiro: Lúmen Júris, 2004 29 RIOS, Roger Raulp. Para um direito democrático da sexualidade. Revista Horizontes Antropológicos, Porto Alegre, ano 12, n. 26, p. 71-100, jul./dez. 2006. 
igualitários e universalistas e desta forma pode produzir a injustiça cultural ou simbólica. As buscas de inserção ou de reconhecimento de outras "sensibilidades jurídicas" 30 nos marcos do processo positivado, estatal - como o direito indígena, a alteridade jurídica, a luta por reconhecimento da "interlegalidade" perante o direito oficial, o qual é resistente no monismo - são as formas manifestas da diversidade revelada, historicamente, nas lutas por reconhecimento e efetividade de direitos. Geertz afirma que as "sensibilidades jurídicas" expressam noções sobre o que é a justiça e sobre as maneiras como ela deve ser exercida. Elas traduzem o sentido de Direito particular a cada cultura e variam conforme o "saber local".

A Justiça para os não indígenas não significa a mesma coisa para os povos indígenas, os quais possuem forma própria de praticar justiça e de requerê-la. Para Santos, ${ }^{31}$ as "formas de juridicidade" estão no campo da pluralidade sociológica do direito, pois o direito estatal é apenas umas das "formas de juridicidade" $e$, deste modo, a "interlegalidade" estaria na articulação e na interpenetração de vários espaços jurídicos misturados. Ghai afirma a importância da postura de interlegalidade no espaço jurídico e a necessidade de "uma genuína integração de leis, decidindo em conjunto o que é valioso em cada cultura"32. Os direitos dos povos indígenas comporiam as decisões do Estado em sentido horizontal: sejam administrativas, legislativas ou judiciais.

\section{DIREITOS INDÍGENAS: RELAÇÕES DIALÓGICAS E HEGEMONIAS} EPISTÊMICAS

Perceber que circunstâncias exógenas impuseram intercursos jurídicorelacionais aos povos indígenas nas últimas décadas no sul e no sudeste do Pará é tarefa também dos Tribunais e do Estado. Os conhecimentos jurídicos não indígenas está em constante interferência no universo de boa parte das relações dos povos indígenas locais tanto interna como externamente a estes povos. $O$ 30 GEERTZ, Cliford Geertz. O saber local: novos ensaios em antropologia interpretativa. Petrópolis: Vozes, 2006.

31 SANTOS, Boaventura de Sousa. Crítica da razão indolente: contra o desperdício da experiência. São Paulo: Cortez, 2001.

32 GHAI, Yashi. Globalização, multiculturalismo e direito. In: SANTOS, Boaventura de Sousa (Org.). Reconhecer para libertar: os caminhos do cosmopolitismo multicultural. Porto: Afrontamento, 2004, p. 470. 
contato de diferentes formas jurídicas é conflituoso como quaisquer contatos nas fronteiras étnicas. Os povos indígenas recebem obrigações normativas "novas" e também introduzem e transportam elementos normativos diferentes e demandas olvidadas e emergentes nos cenários públicos. Esta realidade é experimentada por todos os povos indígenas na região, os quais de diferentes formas foram impactados pelo desenvolvimentismo inaugurado durante a ditadura militar e estendido aos dias atuais.

Hoje, a crescente manifestação de povos indígenas locais por direitos frente ao Estado, empresas públicas e privadas têm lastro no pluralismo, na autonomia e na autodeterminação dos povos indígenas, pois são diretrizes não cumpridas pelo direito hodierno positivado pelo Estado brasileiro. A autonomia é fundamental para gerar outros direitos como autogoverno, autonomia jurídica, autonomia de desenvolvimento, autonomia territorial e outras. García Lozano ${ }^{33}$ revela que a potencialização da autonomia dos povos indígenas é estratégica "para proteger outros direitos, tais como: jurisdição, diversidade cultural e governo próprio, entre outros"34. Os conflitos vivenciados pelos Xikrín, Akrãtikategêe Suruí são exemplos emblemáticos da perpetuação de tais conflitos em lutas para concretizar a autonomia.

São nos marcos da autonomia que o direito indígena tradicional (etnodireito, direito ancestral indígena, autonomias normativas costumeiras orais, tradicionais e ordenadas pela cosmologia indígena) tem lugar. Tal direito não pode ser sobrepujado pelo Estado, ou mesmo silenciado, sob pena de submeter os povos indígenas ao "colonialismo jurídico" 35 materializado no integracionismo jurídico. Rios $^{36}$, identifica "novos direitos" nos interstícios intencionalmente silenciados das normas e a possibilidade emergente e posta pelos novos direitos, ou direitos alargados em possibilidades hermenêuticas pelo novo ambiente constitucional. Aqui, pontos convergentes às conclusões de Rios (2006) podem ser identificados

33 GARCÍA LOZANO, Luisa Fernanda. A jurisprudência indígena da Corte Constitucional colombiana: Produto de práticas emancipadoras ou adaptativas? In: VERDUM, Ricardo (Org.).

Povos Indígenas: Constituições e reformas Políticas na América Latina. Brasília: INESC - Instituto de Estudos socioeconômicos 2009, p. 193-212.

34 Ibdem, p. 200.

35 FERNANDEZ OSCO, Marcelo. La LeyAyllu: justicia de acordos. Tinkasos, Rev. Boliviana de Ciencias Sociales, Jul., 2001, p. 11-28

36 RIOS, Roger Raulp. Para um direito democrático da sexualidade. Revista Horizontes Antropológicos, Porto Alegre, ano 12, n. 26, p. 71-100, jul./dez. 2006. 
no sentido de suscitar o descortinamento e a porosidade do direito positivo estatal que implica tanto a intrusão dos direitos indígenas tradicionais pelas frestas de contradições internas e pelos limites paradigmáticos desnudados, como pela "intromissão" dialógica de outros direitos existentes, insurgidos, não reconhecidos pelo monismo estatal, mas que resistem e insistem no "diálogo". Esta é a proposição da justiça libertadora (paráfrase da "educação libertadora" de Paulo Freire, da concepção e da práxis dialógica do direito no sentido da resistência e a insistência dialógica dos direitos indígenas diante da surdez do Estado e do Judiciário). O processo (e o procedimento) se fará possível no diálogo horizontal para se estabelecer trocas de aprendizagens e enriquecimento mútuo em processo diológico-democrático. A relação dialógica para que flua o diálogo verdadeiro torna-se premissa de justiça em sentido amplo, ainda que a complexidade da relação jurídica seja eivada de interesses essencialmente contraditórios. Diálogo na concepção freiriana é o "encontro entre os homens, mediatizados pelo mundo, para designá-lo". Ao dialogarem os homens chamam o mundo, o transformam, problematizam, criam ação e reflexão. O diálogo neste sentido é necessidade existencial. Ao contrário, o não diálogo consiste em depositar ideias nos outros, impor hierarquias epistêmicas nas quais se revelam os possuidores do conhecimento, a dominação e a opressão destes sobre aqueles considerados "ignorantes absolutos" 37 .

Gadamer $^{38}$ (2000) evidencia o poder do diálogo nas interações humanas, pois o diálogo é a ampliação da singularidade e da experiência da comunhão à qual a razão nos encoraja e existe quando deixa algo em nós que de outro nos encontra e que em nossa experiência ainda não havíamos encontrado e nos transforma. O não diálogo, ou a incapacidade para o diálogo, é aquela que ignora a própria incapacidade de ver o outro e gera a incompreensão, seja pela "incapacidade de ouvir" (incapacidade subjetiva) seja pela falta da "linguagem comum" (incapacidade objetiva); é a repreensão que alguém levanta contra outro que se nega a acompanhar seu pensamento.

37 FREIRE, Paulo. Conscientização: teoria e prática para a libertação: uma introdução ao pensamento de Paulo Freire. São Paulo: Centauro, 1981, p. 81

38 GADAMER, Hans-Georg. A incapacidade para o diálogo. In: ALMEIDA, Custódio Luís S. de; FLICKINGER, Hans-Georg; ROHDEN, Luiz. Hermenêutica filosófica: nas trilhas de HansGeorg Gadamer. Porto Alegre: EDIPURS, 2000, p. 129-139, Coleção Filosofia, 117. 
Santos e Nunes consideram que há o imperativo do diálogo, a promoção do reconhecimento da diferença, porque todas as culturas, assim como as acepções de justiça e direito, são incompletos. Para eles: "Quanto mais alargado for o círculo de reciprocidade definido por uma dada concepção de direitos e de justiça, tanto maior será a capacidade de inclusão de actores e de diálogo e concepções diversos"39. Da mesma matriz dialógica nos fala Grijalva. Para ele, o direito (constitucional) é dialógico,

(...) porque requer a comunicação e a deliberação permanentes para se familiarizar com o entendimento do outro, do diferente. O nível constitucional, no que diz respeito aos direitos das nacionalidades e povos indígenas, deve operar em termos interculturais. Assim, por exemplo, os tribunais constitucionais, os parlamentos, as instituições públicas, incluindo as de defesa dos direitos humanos, devem se converter em verdadeiros foros interculturais, fundamentos e expressões institucionais sólidas da unidade real de um país, e não de sua unificação com base na opressão e na discriminação ${ }^{40}$.

O diálogo é uma arma capaz de afastar o integracionismo jurídico e horizontalizar os direitos de diversas fontes (estatais e indígenas tradicionais), permitindo a concreção da interlegalidade. A interlegalidade torna-se então uma espécie da matriz da interculturalidade instrumentalizada no campo do direito, porque esta já se insere no direito do Estado, embora careça de uma hermenêutica que a transporte para além da mera formalidade abstrata.

\section{CONSIDERAÇÕES FINAIS: APONTAMENTOS INICIAIS DE RUPTURAS}

O não reconhecimento das vozes dos direitos indígenas tradicionais como se revela na indecisão judicial e administrativa envolvendo povo Xikrín, Akrãtikategê e Suruí repercute o impasse do Estado diante dos direitos dos povos indígenas, se as vozes jurídicas estatais não dialogam e desconhecem

39 SANTOS, Boaventura de Sousa; NUNES, João Arriscado. Introdução: para ampliar o cânone do reconhecimento, da diferença e da igualdade. In: SANTOS, Boaventura de Sousa (Org.).

Reconhecer para libertar. Os caminhos do cosmopolitismo multicultural. Porto: Afrontamento, 2004. p. 46, 47

40 GRIJALVA, Agustín. O estado plurinacional e intercultural na constituição equatoriana de 2008. In: VERDUM, Ricardo (Org.). Povos Indígenas: constituições e reformas políticas na América Latina. Brasília: INESC, 2009, p. 119. 
outras possibilidades jurídicas, o que de fato é comum não só na prática judicial, mas também na construção jurisprudencial e teórica do Direito. Ainda que a indecisão seja uma forma de decisão (protelar eficácia de direitos) desfavorável aos povos indígenas nestes casos.

O Estado, legitimado a dirimir conflitos, se encontra vinculado ao princípio constitucional do pluralismo. À medida que olvida o pluralismo - previsto constitucionalmente -, pode tomar para si faces do integracionismo jurídicoprocessual. Segundo estas reflexões, nos conflitos envolvendo povos indígenas, Estado e empresas, devem ter lugar exponencial os direitos indígenas tradicionais no contexto jurídico e normativo do Estado. A medida de como se dá ou não a oitiva dos direitos dos povos indígenas em tais processos, direito dito por eles e não para eles, é a medida do etnocentrismo ou não do Estado. Mede também sua face totalitário-integracionista em relação aos povos indígenas ou, pelo contrário, sua instrumentalidade pluriétnica. Para dirimir tais conflitos, quando estes se judicializam, a "justiça do branco" é chamada para dirimir a controvérsia, e os direitos socioambientais e tradicionais dos povos indígenas raramente são invocados. Prevalecem práticas pouco plurais no judiciário e no Estado em geral, cujas vozes de "autoridades" constroem silêncios forçados nos processos, no conteúdo simbólico das decisões, das políticas públicas, dos empreendimentos privados. As razões jurídicas presentes nos casos dos povos indígenas exemplificados e as implicações (fundamentos) teóricas e jusfilosóficas de referenciais teóricos que "orientam" as decisões judiciais e Estatais caem na vala comum do integracionismo e as palavras dos intérpretes locais (povos indígenas e suas tradições), os direitos humanos dos povos indígenas e a diversidade não se realizam.

A relevância dos direitos indígenas tradicionais, o que em dinamicidade se entrelaça com os direitos indígenas estatais na interlegalidade (administrativa ou jurídico-processual), as demandas de diálogos para localizar o lugar dos direitos indígenas tradicionais na ecologia jurídica do Estado, que se afirma plural, e por efeito nos potenciais de interlegalidade deste raramente se concretizam. Aqui, a crítica aponta para a reinvenção de possibilidades jurídicas e administrativas que maximizem os ideais e os instrumentais de justiça, pois há fundamentos normativos atualizados que podem fazê-lo. 
Os marcos normativos internacionais, constitucionais devem ser profundamente trabalhados. Tais normativas possibilitam questionar o direito de tradição e diversidade, o consentimento livre prévio e informado presente nas declarações ratificadas pelo Brasil e pela Constituição brasileira. A análise das autonomias político-territoriais e o direito indígena tradicional presentes nas reformas constitucionais latino-americanas e os conflitos por efetividade de direitos, a plurinacionalidade, a autodeterminação e o direito indígena tradicional em contexto comparativo ao brasileiro podem trazer luzes em tais conflitos. Tais marcos, criticamente atualizados, apontam para a ruptura com os cânones de um direito integracionista, ou seja, aquele que olvida de partida conhecimentos jurídicos tradicionais dos povos indígenas e que por resultado quer situar a vida dos povos indígenas na adstrita na "legalidade" do empreendedorismo e do desenvolvimentismo estatal ou privado. Afinal, foram as ingerências do Estado (ou entes privados com supedâneo no Estado) que fragmentaram e desintegraram povos indígenas e os territórios tradicionais indígenas, o que lhes trouxe etnocídios físicos e simbólicos.

Hoje as lutas destes povos se inscrevem como heranças de violações ativando direitosrevisitadoseressurgidosemcontextos deimpactos renovadosemovimentos de continuidade. O direito primordial ao território (que remonta ao tempo do império no Brasil com o indigenato) foi violado pelo Estado empreendedor em relação aos três povos mencionados. Os fatos contemporâneos não são meras consequências, mas continuidades com variados graus de intensidade. Renovamse impactos, mas também abrem-se possibilidades de reinterpretar e reescrever direitos para sustentabilidade sociocultural e etnoeconômica destes povos.

Os paradigmas da interlegalidade são fundados na autonomia dos povos indígenas e a autonomia significa - dentre outras coisas - legitimidade de dizerem seu direito a partir de sua localidade cultural, simbólica, ancestral e cosmológica, bem como os direitos de oitiva, consentimento livre, prévio e informado (Convenção 169 da OIT), e o pluralismo societário constitucional brasileiro que afasta o integracionismojurídico em relação a povos indígenas. Estes são parâmetros hermenêuticos que possibilitam legitimar os direitos indígenas 
tradicionais em conflitos destes frente aos interesses Estatais ou privados. De outra forma, as investidas empreendedoristas na Amazônia podem gerar como efeito o legado econômico e cultural insustentável para os povos indígenas e à sua subcidadania, integrando-os de vez à sociedade não indígena. E não parece ser nesta direção que os direitos internacionais e nacionais sobre a diversidade e autonomia apontam.

\section{REFERÊNCIAS}

ALMEIDA, Alfredo Wagner Berno de. Carajás: a guerra dos mapas. Belém: Falangola, 1994.

BRASIL. Justiça Federal, Seção Judiciária de Marabá, Ação Civil Pública, ACP, Processon. Processo 20063901001068-0, 2006.

BRASIL. Fundação Nacional do Índio, FUNAI, Regional Marabá, 2013.

CARDOSO, Wladirson Ronny da Silva. Terra indígena e etnicidade: os usos e a proteção da floresta pelos Kyikatêjê. Dissertação (Mestrado) - Universidade Federal do Pará, Belém, 2009.

CLAVERO, Bartolomé. Derecho Indígena y cultura constitucional en América. Madrid: Siglo

CUNHA, Manuela Carneiro da. Índios no Brasil: história, direitos e cidadania. São Paulo: Ed. Claro Enigma, 2012.

FERNANDES, Rosani de Fátima. Educação Escolar Kyikatêjê: novos caminhos para aprender e ensinar. Dissertação (Mestrado em Direito) - Universidade Federal do Pará, Belém, 2010.

FERNANDEZ OSCO, Marcelo. La LeyAyllu: justicia de acordos. Tinkasos. Rev. Boliviana de Ciencias Sociales, Jul., 2001, p. 11-28.

FERRAZ, Iara. (Coord.). Os Aikewara da Terra Indígena Sororó/Pa. Estudos socioambientais do Componente Indígena no âmbito do Estudo de Impacto Ambiental (EIA) do AHE Santa Isabel. RELATÓRIO FINAL. São Paulo, 2011. Disponível em: http://licenciamento.ibama.gov. br/Hidreletricas/Santa\%20Isabel/1\%20Complementa\%E7\%E30\%20AHE\%20Santa\%20Isabel/ Apendice_28/Relat\%F3rio_Final_Soror\%F3.pdf. Acesso em: 15/01/2014, p. 57.

FREIRE, Paulo. Conscientização: teoria e prática para a libertação: uma introdução ao pensamento de Paulo Freire. São Paulo: Centauro, 1981. 
GADAMER, Hans-Georg. A incapacidade para o diálogo. In: ALMEIDA, Custódio Luís S. de; FLICKINGER, Hans-Georg; ROHDEN, Luiz. Hermenêutica filosófica: nas trilhas de HansGeorg Gadamer. Porto Alegre: EDIPURS, 2000, p. 129-139. (Coleção Filosofia, 117).

GALLOIS, Dominique Tilkin. Terras ocupadas? Territórios? Territorialidades? Disponível em:<www.institutoiep.org.br>. Acesso em: 13 jul. 2013.

GARCÍA LOZANO, Luisa Fernanda. A jurisprudência indígena da Corte Constitucional colombiana: Produto de práticas emancipadoras ou adaptativas? In: VERDUM, Ricardo (Org.). Povos Indígenas: Constituições e reformas Políticas na América Latina. Brasília: INESC Instituto de Estudos socioeconômicos 2009, p. 193-212.

GEERTZ, Cliford Geertz. O saber local: novos ensaios em antropologia interpretativa. Petrópolis: Vozes, 2006.

GHAI, Yashi. Globalização, multiculturalismo e direito. In: SANTOS, Boaventura de Sousa (Org.). Reconhecer para libertar: os caminhos do cosmopolitismo multicultural. Porto: Afrontamento, 2004.

GRIJALVA, Agustín. O estado plurinacional e intercultural na constituição equatoriana de 2008. In: VERDUM, Ricardo (Org.). Povos Indígenas: constituições e reformas políticas na América Latina. Brasília: INESC, 2009, p. 113-134.

HERRERA FLORES, Joaquín. Los derechos humanos en el contexto de la globalización: tres precisiones conceptuales. In: SÁNHEZ RUBIO, David et. al. (Orgs.). Direitos humanos e globalização: fundamentos desde a teoria crítica. Rio de Janeiro: Lúmen Júris, 2004.

LYRA FILHO, Roberto. O que é direito? São Paulo: Brasiliense, 1995. (Coleção. Primeiros Passos, 26).

MARTINS, José de Souza. A chegada do estranho. In: HÉBETTE, Jean (Org.). O cerco está se fechando. Petrópolis: Vozes ; Belém: NAEA/FASE, 1991.

NEVES, Ivânia dos Santos; CORRÊA, Maurício Neves. O povo indígena Aikewára e a Guerrilha do Araguaia: mediação, apropriação e resistência nas fronteiras de identidades. II Conferência Sul Americana/ ALAIC: "Amazônia e o direito de comunicar" 17 a 22 de outubro de 2011 Belém/PA, 2011, p. 4. Disponível em: http://www.unicentro.br/redemc/2011/conteudo/alaic_ artigos/Alaic_Santos_Neves.pdf. Acesso em: 15/01/2014.

RIBEIRO JÚNIOR, Ribamar. Entre deslocamentos e cisões: a trajetória dos Akrãtikategê na luta por sue território. II Coninter, Belo Horizonte, 08 a 11 de outubro/ 2013. Disponível em: www.2coninter.com.br/artigos/pdf/307.pdf?. Acesso em: 15/01/2014. 
RIOS, Roger Raulp. Para um direito democrático da sexualidade. Revista Horizontes Antropológicos, Porto Alegre, ano 12, n. 26, p. 71-100, jul./dez. 2006.

SANTOS, Boaventura de Sousa. Crítica da razão indolente: contra o desperdício da experiência. São Paulo: Cortez, 2001.

Reconhecer para libertar. Os caminhos do cosmopolitismo multicultural. Porto, Portugal: Edições Afrontamento, 2004.

Do pós-moderno ao pós-colonial e para além de um e de outro. In: Congresso LusoAfro-Brasileiro de Ciências Sociais, 7., 2005, Anais. Coimbra, 2005.

. Para uma revolução democrática da justiça. São Paulo: Cortez, 2007.

SANTOS, Boaventura de Sousa e NUNES, João Arriscado. Introdução: para ampliar o cânone do reconhecimento, da diferença e da igualdade. In: SANTOS, Boaventura de Sousa (Org.). Reconhecer para libertar. Os caminhos do cosmopolitismo multicultural. Porto: Afrontamento, 2004. p. 19-51.

SANTOS, Jorge Luis Ribeiro dos. Xikrín versus Vale: direitos olvidados. Tese de Doutorado, Programa de Pós-graduação em Direitos Humanos - PPGD/UFPA, Belém, 2013.

SILVA, Cristhian Teófilo da. Relatos de um certo Ocidente: o indigenismo como orientalismo à americana. Revista de Estudos Paraenses sobre as Américas, v.1, 2009, p. 12-27. Disponível em: <http://www.red.unb.br/index.php/repam/article/view/1367>. Acesso em: 25 abr. 2011.

Indigenismo como ideologia e prática de dominação: apontamentos teóricos para uma etnografia do indigenismo em perspectiva comparada. Disponível em: < http:// www.laced.mn.ufrj.br/indigenismo/.../indigenismo_ideologia_dominacao_cts_2009Cristhian_ Teofilo_da_Silva.pdf>. Acesso em: 20 abr. 2001.

TOURINHO NETO, Fernando da Costa Tourinho. Os povos indígenas e as sociedades nacionais: conflito de normas e superação". In: LIMA, André (Org.). O Direito para o Brasil Socioambiental. Porto Alegre: Sergio Antonio Fabris Editor, 189-229.

WOLKMER, Antônio Carlos. Pluralismo jurídico: fundamentos de uma nova cultura no direito. São Paulo: Alfa-ômega, 1994.

Introdução ao pensamento jurídico crítico. São Paulo: Saraiva, 1995.

Recebido em: mar/2014

Aprovado em: out/2014 